\title{
Início da tuberização, duração do ciclo vegetativo e tolerância ao calor em genótipos de batata
}

\author{
Danilo Hottis Lyra(1), Guilherme Henrique Martins Rodrigues Ribeiro(1), \\ Izabel Cristina Rodrigues de Figueiredo(1), Marcio Lisboa Guedes ${ }^{(1)}$, Otávio Luiz Gomes Carneiro(1), \\ César Augusto Brasil Pereira Pinto ${ }^{(1)}$ e Arione da Silva Pereira(2)
}

\begin{abstract}
(1)UniversidadeFederal de Lavras, Departamento deBiologia, CaixaPostal3037,CEP37200-000 Lavras, MG,Brasil.E-mail:dnalyra@gmail.com, ghmribeiro2@gmail.com, izabelfigueiredo@yahoo.com.br, guedes_gds@yahoo.com.br, otaviogc@hotmail.com, cesarbrasil@dbi.ufla.br (2)Embrapa Clima Temperado, Caixa Postal 403, CEP 96001-970 Pelotas, RS, Brasil. E-mail: arione.pereira@embrapa.br
\end{abstract}

Resumo - O objetivo deste trabalho foi avaliar a relação do tempo para o início da tuberização e da duração do ciclo vegetativo com a tolerância ao calor em batata. Grupos de clones com diferentes tempos para o início de tuberização e durações do ciclo vegetativo foram definidos e avaliados em dois ambientes, e seus índices morfofisiológicos foram estimados em condições de estresse de calor. A amplitude para o início da tuberização foi de 31,8 dias e para a duração do ciclo vegetativo de 30,3 dias. Os grupos de clones formados apresentaram os seguintes parâmetros: tuberização precoce e ciclo vegetativo curto, tuberização precoce e ciclo longo (PL), tuberização tardia e ciclo curto e tuberização tardia e ciclo longo. Em condições de estresse de calor, a produção de tubérculos graúdos do grupo PL apresentou média superior à dos demais grupos. Seis clones (IRF 10-24, IRF 7-61, IRF 2-71, IRF 2-14, IRF 6-104 e IRF 10-44) e três testemunhas ('Markies', CBM 16-16 e CBM 9-10) foram considerados tolerantes ao estresse de calor (média diária de $21,2^{\circ} \mathrm{C}$ ) e responderam favoravelmente ao ambiente com temperaturas amenas (média diária de $19,0^{\circ} \mathrm{C}$ ). A partição de matéria seca para os tubérculos foi mais rápida nos clones do grupo PL. Os clones de tuberização precoce e ciclo vegetativo longo apresentaram maior tolerância ao calor, com maior produção de tubérculos do que os demais grupos.

Termos para indexação: Solanum tuberosum, estresse térmico, índices morfofisiológicos, tolerância.

\section{Tuber initiation, duration of the vegetative cycle and heat tolerance in potato genotypes}

\begin{abstract}
The objective of this work was to determine the relationship of the time for tuber initiation and of the duration of the vegetative cycle with heat tolerance in potato. Clone groups with different tuber initiation times and duration of the vegetative cycle were defined and evaluated in two environments, and their morphophysiological indices were determined under heat stress conditions. The amplitude for the beginning of tuberization was 31.8 days, and for the duration of vegetative cycle was 30.3 days. The formed groups of clones showed the following parameters: early tuberization and short cycle, early tuberization and long cycle (PL), late tuberization and short cycle, and late tuberization and long cycle. Under heat stress conditions, the production of large tubers of the PL group was higher than that of the other groups. Six clones (IRF 10-24, IRF 7-61, IRF 2-71, IRF 2-14, IRF 6-104, and IRF 10-44) and three checks ('Markies', CBM 16-16, and CBM 9-10) were considered tolerant to heat stress $\left(21.2^{\circ} \mathrm{C}\right.$ daily average), and responded favorably to environment at mild temperatures $\left(19.0^{\circ} \mathrm{C}\right.$ daily average). Dry matter partitioning to the tubers was faster in the PL clone group. Clones of early tuberization and long vegetative cycle showed higher tolerance to heat stress, with higher tuber production than the other groups.
\end{abstract}

Index terms: Solanum tuberosum, heat stress, morphophysiological indices, tolerance.

\section{Introdução}

A produtividade de batata em regiões tropicais e subtropicais é reduzida devido ao estresse térmico por calor (Ribeiro et al., 2014). Temperaturas diárias médias (dia e noite) acima de $21^{\circ} \mathrm{C}$ são consideradas altas para o cultivo da batata. Isto pode ocorrer quando as temperaturas diurnas e noturnas estão entre 27 e $15^{\circ} \mathrm{C}$ (Haverkort \& Verhagen, 2008). Altas temperaturas causam redução da produtividade e da massa de matéria seca de tubérculos, além de depreciar o produto em razão de desordens fisiológicas, como 
rachaduras, "embonecamentos" e "coração-oco" (Rykaczewska, 2015). Além disso, ocorre inibição da tuberização e redução da partição de fotoassimilados para os tubérculos (Aien et al., 2011).

Há vários relatos na literatura sobre a redução da produção de tubérculos em consequência de altas temperaturas. Nas condições ambientais brasileiras, Lambert et al. (2006a) observaram redução do número e da massa de tubérculos, que resultou em decréscimos de até $58 \%$ da produção e de $25 \%$ da percentagem de tubérculos graúdos. Em outro trabalho, conduzido em condições semelhantes, Menezes et al. (1999) mostraram, também, a redução de $25,5 \%$ da produtividade de tubérculos.

No entanto, há vários níveis de tolerância ao calor, associados aos diferentes genótipos, que podem ser explorados em programas de melhoramento (Zommick et al., 2014). Assim, para que a seleção seja cada vez mais eficiente, é importante conhecer os mecanismos e processos que conferem níveis elevados de tolerância, como a seleção de clones com base no início da tuberização e na duração do ciclo vegetativo (Jha et al., 2014).

O controle da tuberização está relacionado a fatores fisiológicos, bioquímicos e genéticos (Fischer et al., 2008), e há variações nos genótipos de batata quanto ao início de tuberização (Morris et al., 2014) sob estresse de calor. Isso ocorre, também, quanto à duração do ciclo vegetativo (Rodrigues et al., 2009; Silva et al., 2009). O início da tuberização e a duração do ciclo vegetativo interferem na alocação de recursos nas plantas de batata. Assim, a utilização de índices morfofisiológicos, tais como índice de colheita e taxa de crescimento da cultura, podem contribuir para o entendimento da taxa de acúmulo e partição de matéria seca para as folhas e tubérculos e a taxa de senescência da cultura (Hancock et al., 2014), principalmente, quando submetidos ao estresse térmico.

A obtenção de cultivares tolerantes ao calor poderia auxiliar no aumento de produtividade nas atuais áreas de plantio, além de possibilitar a produção de matéria prima de qualidade para a indústria de processamento (Pinto et al., 2010). Para isto, algumas estratégias de melhoramento devem ser utilizadas, como a seleção em condições favoráveis e adversas, na busca por genótipos tolerantes ao calor e responsivos a temperaturas amenas (Benites \& Pinto, 2011). Outra estratégia pode envolver o aumento da duração do ciclo vegetativo (Silva \& Pinto, 2005).

O objetivo deste trabalho foi determinar a relação do tempo para o início da tuberização (precoce/tardia) e da duração do ciclo vegetativo (curto/longo) com a tolerância ao calor, em batata.

\section{Material e Métodos}

A pesquisa foi desenvolvida em área experimental do Departamento de Biologia (DBI) da Ufla, em Lavras, MG $\left(21^{\circ} 13^{\prime} 55^{\prime \prime S}\right.$ e $44^{\circ} 57^{\prime} 43^{\prime \prime W}$, altitude de $\left.925 \mathrm{~m}\right)$ e em Bom Repouso, MG (22²8'16"S, 4608'42"W, altitude de $1.375 \mathrm{~m}$ ). A população-base utilizada neste estudo constituiu-se de 117 clones, gerados no programa de melhoramento da Ufla, oriundos do cruzamento entre clones (Solanum tuberosum ssp. tuberosum) selecionados quanto à tolerância ao calor por Lambert et al. (2006a) e Benites \& Pinto (2011).

Como testemunhas sensíveis ao calor utilizaram-se as cultivares Agata e Asterix. As testemunhas tolerantes ao calor foram a cultivar Markies e três clones (CBM 24-06, CBM 16-16 e CBM 09-10) do Programa de Melhoramento de Batata da Ufla.

Para avaliar o início da tuberização, os 117 clones e as seis testemunhas foram cultivados em casa de vegetação do DBI-Ufla, de janeiro a março de 2013 (experimento 1). A temperatura e a umidade relativa do ar foram monitoradas por um termo-higrômetro digital, às 7:00, 10:00, 14:00 e 18:00 h. Tubérculos com diâmetro de aproximadamente $2 \mathrm{~cm}$ foram plantados em vasos de plástico de $10 \mathrm{~cm}$ de diâmetro, que continham substrato organo-mineral. As regas foram realizadas manualmente, duas vezes por dia, e a adubação foi feita no plantio com $5 \mathrm{~g}$ de fertilizante formulado 04-14-08 (N, $\left.\mathrm{P}_{2} \mathrm{O}_{5}, \mathrm{~K}_{2} \mathrm{O}\right)$ em cada vaso de plástico.

Utilizou-se delineamento experimental inteiramente casualizado, com cinco repetições e uma planta por parcela. As datas de emergência das plantas foram anotadas e, após três semanas, iniciou-se a avaliação da tuberização. Para isso, retirou-se cada planta do vaso e observou-se a presença ou ausência de pelo menos um tubérculo, com diâmetro transversal duas vezes maior do que o diâmetro do estolão. Imediatamente, as plantas foram replantadas e irrigadas abundantemente. A avaliação foi feita a cada três dias, até que fosse observada a tuberização.

Pesq. agropec. bras., Brasília, v.50, n.7, p.582-592, jul. 2015 DOI: $10.1590 / \mathrm{S} 0100-204 X 2015000700008$ 
Para avaliação do ciclo vegetativo dos 117 clones e seis testemunhas, realizou-se um experimento em campo, de janeiro a abril de 2013, na área experimental do DBI-Ufla, em Lavras, MG (experimento 2). Os dados meteorológicos de temperatura foram monitorados pela Estação Climatológica de Lavras/ Ufla. Um delineamento experimental de blocos completos ao acaso foi utilizado com três repetições e parcela de cinco plantas, espaçadas de $0,30 \times 0,80 \mathrm{~m}$. As datas de emergência e seca das ramas das plantas foram anotadas quando a maioria emergiu ou secou, respectivamente, sendo o ciclo vegetativo o número de dias da emergência à senescência natural da parte aérea. Além disso, anotaram-se os seguintes dados: produtividade total dos tubérculos (grama por planta); produtividade de tubérculos graúdos, com diâmetro transversal acima de $45 \mathrm{~mm}$ (grama por planta); e massa específica dos tubérculos [MET = massa no ar/ (massa no ar - massa na água)], medidos em balança hidrostática.

Com base nos dados dos experimentos anteriores, definiram-se quatro grupos de clones, com diferentes inícios de tuberização e durações do ciclo vegetativo. Cada grupo se constituiu de cinco clones representativos, escolhidos com base nas médias dos dois caracteres, isto é, clones abaixo da média de início da tuberização foram considerados precoces e acima da média, tardios. O mesmo fato ocorreu para a duração do ciclo vegetativo, em que os clones com ciclos menores do que a média foram considerados clones de ciclo curto, e aqueles acima da média considerados como clones de ciclo longo. Assim, os seguintes grupos foram formados: tuberização precoce e ciclo curto (PC), tuberização precoce e ciclo longo (PL), tuberização tardia e ciclo curto (TC) e tuberização tardia e ciclo longo (TL).

Os cinco clones de cada grupo (PC, PL, TC e TL) foram plantados em dois experimentos distintos, no período de setembro/2013 a janeiro/2014. A testemunha 'Agata' não foi utilizada. Os experimentos foram conduzidos em duas condições de temperatura com estresse de calor ou sem estresse de calor -, um realizado em Lavras, MG (temperatura média diária de $21,2^{\circ} \mathrm{C}$ ), na área experimental do DBI-Ufla (experimento 3), e outro em Bom Repouso, MG (temperatura média diária de $19,0^{\circ} \mathrm{C}$ ), em área de produtor de batata (experimento 3). Utilizou-se o delineamento experimental de blocos completos ao acaso, com três repetições e cinco plantas por parcela, espaçadas de $0,30 \times 0,80 \mathrm{~m}$. Durante o ciclo da cultura, as temperaturas foram monitoradas em ambos os experimentos. Avaliaram-se os mesmos caracteres do experimento 2 .

Para o manejo dos ensaios em campo, utilizou-se a adubação de $3.500 \mathrm{~kg} \mathrm{ha}^{-1}$ de fertilizante formulado 04-14-08 (N, $\left.\mathrm{P}_{2} \mathrm{O}_{5}, \mathrm{~K}_{2} \mathrm{O}\right)$, ao plantio; a adubação de cobertura foi feita no momento da amontoa, com $400 \mathrm{~kg} \mathrm{ha}^{-1}$ de fertilizante formulado 20-05-20. $\mathrm{O}$ preparo de solo foi feito de maneira usual para a cultura, com aração seguida de gradagem e enxada rotativa, e o manejo de irrigação, por aspersão, foi feito com turno de rega fixo de sete dias. As pulverizações com defensivos para controle de pragas e doenças foram realizadas no sulco e na parte aérea, conforme a prática dos produtores na região. $\mathrm{O}$ estado fisiológico e fitossanitário dos tubérculos-sementes utilizados nos plantios, nos ensaios de campo, bem como o tamanho dos tubérculos foi padronizado.

Para avaliar o desempenho dos clones no ambiente com ou sem estresse de calor, quanto à produção de tubérculos e peso específico dos tubérculos, as médias foram plotadas tanto no ambiente desfavorável - Lavras (eixo x ) -, como no ambiente em condição sem estresse de calor - Bom Repouso (eixo y). Duas retas traçadas na média de todos os genótipos, em cada ambiente, distribuem os genótipos em quatro quadrantes: aqueles tolerantes ou sensíveis ao calor (acima ou abaixo da média do eixo $\mathrm{x}$ ), e aqueles responsivos ou não a temperaturas amenas (acima ou abaixo da média do eixo y) (Lambert et al., 2006b).

Para estimar os índices morfofisiológicos dos diferentes grupos de clones, um ensaio (experimento 4) foi realizado de setembro a dezembro de 2013, na área experimental do DBI-UFLA, em Lavras, MG, em condições semelhantes às encontradas no experimento 3. Foram tomados dois clones representativos de cada grupo (PC, PL, TC e TL), diferentes dos utilizados anteriormente e, como testemunhas, as cultivares Asterix e Markies. Amostragens de quatro épocas foram efetuadas aos 30, 50, 70 e 90 dias após a emergência (DAE). Cada época de colheita foi considerada como um experimento em delineamento de blocos completos ao acaso, com três repetições. As parcelas experimentais constituíram-se de duas plantas espaçadas de $0,30 \times 0,80 \mathrm{~m}$. As parcelas foram distanciadas de $0,50 \mathrm{~m}$ e, entre elas, foi plantado um 
tubérculo da 'Asterix', com a finalidade de minimizar o efeito compensatório causado pelo número reduzido de plantas na parcela.

Determinaram-se os índices morfofisiológicos descritos a seguir. Massa de matéria seca (MS) da parte aérea ( $\mathrm{g}$ por planta), obtida pela secagem das folhas e hastes em estufa a $60^{\circ} \mathrm{C}$, com fluxo de ar forçado até a obtenção de massa constante. Massa de MS dos tubérculos ( $\mathrm{g}$ por planta), obtida pela secagem dos tubérculos em estufa a $60^{\circ} \mathrm{C}$, com fluxo de ar forçado até a obtenção de massa constante. Índice de colheita (\%), que é a relação entre a matéria seca particionada para os tubérculos e a matéria seca total da planta, pela equação $\mathrm{IC}_{\mathrm{i}}(\%)=\left[\mathrm{W}_{\text {tubi }} /\left(\mathrm{W}_{\text {tubi }}+\mathrm{W}_{\text {ramai }}\right) \times 100\right]$, em que: $\mathrm{IC}_{\mathrm{i}}$ é a partição de matéria seca para os tubérculos observada, referente à época de amostragem $\mathrm{i} ; \mathrm{W}_{\text {tubi }}$ é a matéria seca dos tubérculos, à época de colheita $i$; $\mathrm{W}_{\text {ramai }}$ é a matéria seca da parte aérea, à época de colheita i. Taxa de crescimento médio da cultura (TCC, g MS por planta por dia), para cada época de amostragem, que foi estimada pela equação $\mathrm{TCC}=\mathrm{W}_{\mathrm{pli}}-\mathrm{W}_{\text {pli- }-1} / \mathrm{DAE}_{\mathrm{i}}-\mathrm{DAE}_{\mathrm{i}-\mathrm{l}}$, em que: $\mathrm{W}_{\mathrm{pli}}$ é a matéria seca da planta (parte aérea e tubérculos), à época de colheita $\mathrm{i} ; \mathrm{W}_{\text {pli-1 }}$ é a matéria seca da planta (parte aérea e tubérculos), à época de colheita i-1; $\mathrm{DAE}_{\mathrm{i}}$ é o número de dias após a emergência, à época de colheita $\mathrm{i} ; \mathrm{DAE}_{\mathrm{i}-1}$ é o número de dias após a emergência, à época de colheita i-1. Taxa de tuberização (TUB, g MS por planta por dia), para cada época de amostragem, que foi estimada pela equação: $\mathrm{TUB}_{\mathrm{i}}=\mathrm{W}_{\text {tub }_{\mathrm{i}}}-\mathrm{W}_{\text {tubi-1 }_{\mathrm{i}}} / \mathrm{DAE}_{\mathrm{i}}-\mathrm{DAE}_{\mathrm{i}-\mathrm{I}}$, em que: $\mathrm{TUB}_{\mathrm{i}}$ é a taxa de tuberização observada, à época de colheita $\mathrm{i} ; \mathrm{W}_{\text {tubi }}$ é a matéria seca dos tubérculos, à época de colheita $\mathrm{i}$; e $W_{\text {tubi-1 }}$ é a matéria seca dos tubérculos, à época de colheita i-1. A taxa de tuberização reflete o quanto de matéria seca de tubérculos é produzida por unidade de área foliar, por dia. Esta é uma forma indireta de calcular a relação fonte-dreno para os tubérculos da planta, ou seja, a fotossíntese líquida (Silva et al., 2009).

Os dados dos experimentos foram submetidos à análise de variância por meio do programa computacional SAS 9.1 (SAS Institute, Cary, NC, EUA). Todos os gráficos foram gerados no programa Statistica 12 (Statsoft, Tulsa, OK, EUA). Os coeficientes de correlação fenotípica de Pearson foram estimados entre os dados de início da tuberização (experimento 1), duração do ciclo vegetativo, período de enchimento dos tubérculos, produção total de tubérculos e massa específica dos vinte clones pertencentes aos quatro grupos avaliados no experimento 2 e no experimento 3/Lavras. Para os índices morfofisiológicos, as médias dos caracteres das quatro épocas de colheitas, de todos os grupos e testemunhas, foram submetidos à análise de regressão polinomial de segundo grau.

\section{Resultados e Discussão}

Durante o período de tuberização, as médias das temperaturas mínimas, médias e máximas foram $19,1,27,2$ e $35,7^{\circ} \mathrm{C}$, o que caracteriza o forte estresse de calor. Houve diferença significativa entre os 117 clones avaliados quanto ao início da tuberização. A tuberização mais precoce ocorreu aos 22 dias após emergência (DAE) no clone IRF 7-7, enquanto o clone IRF 13-18 foi o mais tardio, com 54 DAE. Isto resultou em amplitude de 32 dias, o que mostra a vasta variabilidade quanto ao início de tuberização sob estresse de calor.

Durante a avaliação do ciclo vegetativo, a temperatura média do ar foi de $21,4^{\circ} \mathrm{C}$, com máxima de $29,6^{\circ} \mathrm{C}$, pico de $35,5^{\circ} \mathrm{C}$, e mínimas de $16,3^{\circ} \mathrm{C}$, o que caracteriza o estresse de calor. Houve diferenças significativas entre os 117 clones avaliados quanto à duração do ciclo vegetativo. O clone IRF 1-52 apresentou o ciclo vegetativo mais longo (104 DAE), enquanto o IRF 4-26 o mais curto (73,7 DAE), com amplitude de 30,3 dias; isto evidencia a variabilidade para o caráter. Variações quanto à duração do ciclo vegetativo e tolerância ao calor também foram relatadas por Mienie \& Ronde (2008), em estudo sobre 12 genótipos de batata, com base na sensibilidade térmica das folhas a 37 e $45^{\circ} \mathrm{C}$. Estes autores descreveram que as cultivares de ciclo longo foram mais tolerantes ao calor do que as de ciclo curto.

Nos quatro grupos de acessos selecionados, a partir dos resultados dos dois primeiros experimentos quanto ao início da tuberização e duração do ciclo vegetativo, verificou-se diferença média de 16 dias para início da tuberização, entre acessos de tuberização precoce e tardia, e 15,5 dias na duração do ciclo vegetativo, entre acessos de ciclos curto e longo (Tabela 1). Os quatro grupos também diferiram quanto ao período de enchimento dos tubérculos (diferença entre o início da tuberização e a duração do ciclo vegetativo), cuja 
amplitude foi de 24,7 dias entre os grupos PL e TC (Tabela 1).

Durante a avaliação dos grupos de genótipos selecionados (experimento 3), a temperatura mínima foi de $15,3^{\circ} \mathrm{C}$, a média de $21,2^{\circ} \mathrm{C}$, e as máximas se mantiveram em torno de $30^{\circ} \mathrm{C}$, com pico de $34,5^{\circ} \mathrm{C}$. Em Bom Repouso, observaram-se temperaturas mais baixas do que o ensaio em Lavras, e a temperatura mínima foi de $14,6^{\circ} \mathrm{C}$, a média de $19,0^{\circ} \mathrm{C}$, e a máxima de $25,4^{\circ} \mathrm{C}$. Estes ambientes foram considerados contrastantes, uma vez que a temperatura ideal para a cultura da batata está entre 14 e $20^{\circ} \mathrm{C}$, intervalo que favorece a fotossíntese, reduz a respiração da planta e favorece o acúmulo de reservas (Levy \& Veilleux, 2007).

Correlação positiva e significativa de 0,48 foi obtida entre o início da tuberização e o ciclo vegetativo (experimento 2), o que indica que os clones com

Tabela 1. Início da tuberização e duração do ciclo vegetativo, expressos em dias após a emergência, e período de enchimento dos tubérculos (PEN) dos quatro grupos de clones, bem como produção de tubérculos graúdos por planta (PRODG) e massa específica dos tubérculos nos experimentos de Lavras e Bom Repouso ${ }^{(1)}$.

\begin{tabular}{|c|c|c|c|c|c|c|c|}
\hline \multirow[t]{2}{*}{ Genótipo } & \multirow{2}{*}{\multicolumn{2}{|c|}{$\begin{array}{l}\text { Início tuberização Ciclo vegetativo } \\
\text {---(dias após a emergência, DAE)--- }\end{array}$}} & \multirow{2}{*}{$\begin{array}{l}\text { PEN } \\
\text { (dias) }\end{array}$} & \multicolumn{2}{|c|}{ PRODG (g por planta) } & \multicolumn{2}{|c|}{ Massa específica dos tubérculos } \\
\hline & & & & Lavras & Bom repouso & Lavras & Bom Repouso \\
\hline & \multicolumn{7}{|c|}{ Grupo tuberização precoce e ciclo vegetativo curto } \\
\hline IRF 4-26 & $25,0 \mathrm{a}$ & $73,6 \mathrm{a}$ & $48,6 \mathrm{~b}$ & $466,7 \mathrm{a}$ & $360,0 \mathrm{a}$ & $1,0674 \mathrm{~b}$ & $1,0810 \mathrm{~b}$ \\
\hline IRF 6-104 & $27,8 \mathrm{a}$ & $76,6 \mathrm{a}$ & $48,8 b$ & $783,3 b$ & $590,0 \mathrm{~b}$ & $1,0609 \mathrm{a}$ & $1,0727 \mathrm{a}$ \\
\hline IRF 9-18 & $28,4 \mathrm{a}$ & $75,6 \mathrm{a}$ & $47,2 b$ & $333,3 \mathrm{a}$ & $330,0 \mathrm{a}$ & $1,0762 \mathrm{c}$ & $1,0881 b$ \\
\hline IRF 9-68 & $27,0 \mathrm{a}$ & $82,0 \mathrm{a}$ & $55,0 \mathrm{~b}$ & $493,3 a$ & $540,0 \mathrm{~b}$ & $1,0658 \mathrm{a}$ & $1,0797 b$ \\
\hline IRF $14-31$ & $25,7 \mathrm{a}$ & $82,0 \mathrm{a}$ & $56,2 b$ & $584,2 \mathrm{a}$ & $426,7 \mathrm{a}$ & $1,0577 \mathrm{a}$ & $1,0720 \mathrm{a}$ \\
\hline \multirow[t]{2}{*}{ Média } & $26,7 \mathrm{a}$ & $77,9 \mathrm{a}$ & $51,2 \mathrm{~b}$ & $532,1 \mathrm{a}$ & $449,3 \mathrm{a}$ & $1,0655 \mathrm{a}$ & $1,0787 \mathrm{~b}$ \\
\hline & \multicolumn{7}{|c|}{ Grupo tuberização precoce e ciclo vegetativo longo } \\
\hline IRF $10-24$ & $28,8 \mathrm{a}$ & $91,3 b$ & $62,5 \mathrm{c}$ & $1266,7 \mathrm{c}$ & $840,0 \mathrm{~b}$ & $1,0674 b$ & $1,0751 \mathrm{a}$ \\
\hline IRF 32-02 & $26,5 \mathrm{a}$ & $90,0 \mathrm{~b}$ & $63,5 \mathrm{c}$ & $360,0 \mathrm{a}$ & $320,0 \mathrm{a}$ & $1,0560 \mathrm{a}$ & $1,0779 b$ \\
\hline IRF 7-61 & $29,4 a$ & $97,3 \mathrm{c}$ & $67,9 \mathrm{c}$ & $1053,3 \mathrm{c}$ & $926,7 b$ & $1,0781 \mathrm{c}$ & $1,0733 \mathrm{a}$ \\
\hline IRF 9-44 & $32,0 \mathrm{a}$ & $98,6 \mathrm{c}$ & $66,6 \mathrm{c}$ & $726,7 b$ & $500,0 \mathrm{a}$ & $1,0768 \mathrm{c}$ & $1,0820 \mathrm{~b}$ \\
\hline IRF $10-44$ & $26,2 \mathrm{a}$ & $87,6 \mathrm{a}$ & $61,4 \mathrm{c}$ & $550,0 \mathrm{a}$ & $686,7 b$ & $1,0567 \mathrm{a}$ & $1,0722 \mathrm{a}$ \\
\hline \multirow[t]{2}{*}{ Média } & $28,5 \mathrm{a}$ & $92,9 b$ & $64,4 \mathrm{c}$ & $791,3 b$ & $654,6 b$ & $1,0670 \mathrm{a}$ & $1,0760 \mathrm{~b}$ \\
\hline & \multicolumn{7}{|c|}{ Grupo tuberização tardia e ciclo vegetativo curto } \\
\hline IRF $1-08$ & $44,7 \mathrm{~b}$ & $87,3 \mathrm{a}$ & $31,9 \mathrm{a}$ & $746,7 b$ & $483,3 \mathrm{a}$ & $1,0695 b$ & $1,0781 b$ \\
\hline IRF $12-34$ & $42,8 b$ & $81,3 \mathrm{a}$ & $38,8 \mathrm{a}$ & $276,7 \mathrm{a}$ & $250,0 \mathrm{a}$ & $1,0753 \mathrm{c}$ & $1,0812 b$ \\
\hline IRF 6-46 & $43,5 b$ & $83,6 \mathrm{a}$ & $41,5 \mathrm{a}$ & $496,7 \mathrm{a}$ & $556,7 \mathrm{~b}$ & $1,0704 b$ & $1,0822 b$ \\
\hline IRF 9-35 & $44,6 \mathrm{~b}$ & $86,0 \mathrm{a}$ & $41,3 a$ & $433,3 a$ & $380,0 \mathrm{a}$ & $1,0687 \mathrm{~b}$ & $1,0859 \mathrm{~b}$ \\
\hline IRF 2-45 & $38,0 \mathrm{~b}$ & $85,0 \mathrm{a}$ & $45,0 \mathrm{~b}$ & $326,7 \mathrm{a}$ & $156,7 \mathrm{a}$ & $1,0604 \mathrm{a}$ & $1,0711 \mathrm{a}$ \\
\hline \multirow[t]{2}{*}{ Média } & $42,7 b$ & $84,6 \mathrm{a}$ & $39,7 \mathrm{a}$ & $456,0 \mathrm{a}$ & $365,3 \mathrm{a}$ & $1,0688 \mathrm{a}$ & $1,0797 \mathrm{~b}$ \\
\hline & \multicolumn{7}{|c|}{ Grupo tuberização tardia e ciclo vegetativo longo } \\
\hline IRF 1-52 & $40,7 \mathrm{~b}$ & $104,0 \mathrm{c}$ & $63,2 \mathrm{c}$ & $256,7 \mathrm{a}$ & $580,0 \mathrm{~b}$ & $1,0552 \mathrm{a}$ & $1,0803 \mathrm{~b}$ \\
\hline IRF 1-41 & $53,5 b$ & $102,0 \mathrm{c}$ & $63,6 \mathrm{c}$ & $333,3 \mathrm{a}$ & $560,0 \mathrm{~b}$ & $1,0630 \mathrm{a}$ & $1,0772 b$ \\
\hline IRF 17-02 & $41,7 b$ & $99,6 \mathrm{c}$ & $57,9 \mathrm{c}$ & $103,3 a$ & $396,7 \mathrm{a}$ & $1,0626 a$ & $1,0729 a$ \\
\hline IRF 2-14 & $44,7 b$ & $97,6 \mathrm{c}$ & $52,9 b$ & $856,7 b$ & $686,7 b$ & $1,0673 b$ & $1,0711 \mathrm{a}$ \\
\hline IRF 2-71 & $42,7 \mathrm{~b}$ & $100,3 \mathrm{c}$ & $57,5 \mathrm{c}$ & $950,0 \mathrm{c}$ & $746,7 b$ & $1,0619 \mathrm{a}$ & $1,0744 \mathrm{a}$ \\
\hline \multirow[t]{2}{*}{ Média } & $44,7 \mathrm{~b}$ & $100,7 \mathrm{c}$ & $59,0 \mathrm{c}$ & $500,0 \mathrm{a}$ & $594,0 \mathrm{~b}$ & $1,0619 \mathrm{a}$ & $1,0751 \mathrm{~b}$ \\
\hline & \multicolumn{7}{|c|}{ Testemunhas } \\
\hline CBM 09-10 & $48,7 \mathrm{~b}$ & $97,0 \mathrm{c}$ & $48,3 b$ & $780,0 \mathrm{~b}$ & $830,0 \mathrm{~b}$ & $1,0786 \mathrm{c}$ & $1,0806 \mathrm{~b}$ \\
\hline CBM 16-16 & $38,2 b$ & $93,0 \mathrm{~b}$ & $54,8 \mathrm{~b}$ & $793,3 b$ & $823,3 b$ & $1,0780 \mathrm{c}$ & $1,0807 \mathrm{~b}$ \\
\hline CBM 24-06 & $34,0 \mathrm{a}$ & $84,3 \mathrm{a}$ & $50,3 b$ & $760,0 \mathrm{~b}$ & $730,0 b$ & $1,0614 a$ & $1,0731 \mathrm{a}$ \\
\hline Agata & $29,0 \mathrm{a}$ & $78,5 \mathrm{a}$ & $49,5 b$ & - & - & - & - \\
\hline Asterix & $33,0 \mathrm{a}$ & $81,0 \mathrm{a}$ & $48,0 \mathrm{~b}$ & $233,3 a$ & $413,3 a$ & $1,0544 \mathrm{a}$ & $1,0707 \mathrm{a}$ \\
\hline Markies & $33,0 \mathrm{a}$ & $78,5 \mathrm{a}$ & $45,5 b$ & $1036,7 \mathrm{c}$ & $583,3 b$ & $1,0623 \mathrm{a}$ & $1,0726 \mathrm{a}$ \\
\hline
\end{tabular}

${ }^{(1)}$ Médias seguidas por letras iguais, nas colunas, pertencem ao mesmo grupo, pelo teste de Scott Knott, a 5\% de probabilidade. 
tuberização tardia tendem a ter ciclo vegetativo mais longo (Tabela 2). Entre o início da tuberização e o período de enchimento de tubérculos, as correlações foram de $-0,47$ (experimento 2) e $-0,78$ (experimento $3 /$ Lavras). Estes resultados indicam que clones com tuberização precoce apresentam maior período de enchimento dos tubérculos. As correlações entre a duração do ciclo vegetativo e a produção de tubérculos foram de 0,55 (experimento 2) e 0,54 (experimento 3/ Lavras). Silva \& Pinto (2005) também relataram que o ciclo vegetativo mais longo aumenta o período de enchimento dos tubérculos, o que resulta em maior produção de tubérculos.

A produção de tubérculos graúdos do grupo $\mathrm{PL}$ apresentou média superior à dos demais grupos, na condição de estresse de calor, em Lavras. Na condição sem estresse de calor, em Bom Repouso, os grupos PL e TL apresentaram média superior quanto ao mesmo caráter (Tabela 1). Resultado similar foi observado por Silva et al. (2009) e Rolando et al. (2015), quanto à maior produção de tubérculos dos clones de ciclo vegetativo longo, em razão da maior duração da área foliar. Segundo estes autores, genótipos que apresentam essa característica tendem a manter por mais tempo a área foliar fotossinteticamente ativa, o que faz com que esses genótipos sejam úteis aos programas de melhoramento de batata que visam à seleção de clones tolerantes ao calor e seca.

As médias de massa específica de tubérculos, em Lavras, variaram de 1,054 a 1,079 (média de 18,6\% de teor de matéria seca) e não apresentaram diferenças significativas entre os grupos de clones (Tabela 1). Em Bom Repouso, as médias para o mesmo caráter

Tabela 2. Coeficientes de correlação fenotípica de Pearson, quanto ao desempenho dos vinte clones pertencentes aos quatro grupos, do experimento 2 (diagonal inferior) e experimento 3/Lavras (diagonal superior), para as variáveis início da tuberização (TUB), duração do ciclo vegetativo (CL), período de enchimento dos tubérculos (PEN), produção total de tubérculos (g por planta) (PROD) e massa específica dos tubérculos (MES).

\begin{tabular}{lccccc}
\hline & TUB & CL & PEN & PROD & MES \\
\hline TUB & - & $0,12^{\text {ns }}$ & $-0,78^{* *}$ & $-0,21^{\text {ns }}$ & $0,07^{\text {ns }}$ \\
CL & $0,48^{*}$ & - & $0,50^{*}$ & $0,54^{*}$ & $0,23^{\text {ns }}$ \\
PEN & $-0,47^{*}$ & $0,50^{*}$ & - & $0,52^{*}$ & $0,08^{\text {ns }}$ \\
PROD & $0,08^{\text {ns }}$ & $0,55^{*}$ & $0,44^{*}$ & - & $0,34^{\text {ns }}$ \\
MES & $0,08^{\text {ns }}$ & $-0,25^{\text {ns }}$ & $-0,35^{\text {ns }}$ & $0,04^{\text {ns }}$ & - \\
\hline
\end{tabular}

${ }^{\mathrm{n}} \mathrm{Não}$ significativo. ${ }^{* *} \mathrm{e}$ S Significativo a 1 e $5 \%$, respectivamente, pelo teste $\mathrm{F}$. variaram de 1,071 a 1,088 (média de 21,1\% de teor matéria seca) e não apresentaram diferenças significativas entre os grupos de clones (Tabela 1). Conforme Ribeiro et al. (2014), tubérculos com massa específica em torno de 1,060 são adequados apenas para cozimento, porém, acima de 1,077 podem ser utilizados na indústria de pré-fritas congeladas ou para o preparo de massas. Assim, evidenciou-se que, em Lavras, os tubérculos não apresentaram qualidade adequada para o processamento industrial em nenhum dos grupos de clones avaliados.

Somente a 'Asterix' apresentou produção inferior à das demais testemunhas, nos dois locais. A que apresentou maior produção de tubérculos graúdos foi 'Markies' e, quanto à massa específica, as testemunhas CBM 16-16 e CBM 9-10 superaram as demais. Tal resultado é explicado pelo fato de os clones utilizados serem tolerantes ao calor conforme Lambert et al. (2006a) e, também, pelo fato de a cultivar Markies apresentar bom desempenho em condições de estresse de calor.

Os clones que se encontram no quadrante I (Figura 1) foram responsivos às temperaturas amenas; eles apresentaram médias de produção de tubérculos e massa específica mais altas sob temperaturas elevadas e são os clones desejados. Quanto à produção de tubérculos, a maioria dos clones do grupo PL situouse neste quadrante (Figura 1A). O maior período de enchimento de tubérculos do grupo PL (Tabela 1) leva a uma média superior de produção $(28,5 \%)$ a dos demais grupos, o que garante o melhor desempenho do grupo. Essa maior performance dos clones do grupo PL mostra que seus comportamentos são mais previsíveis e que eles sofrem menos os impactos negativos do estresse de calor, o que lhes assegura melhor rendimento sob diferentes condições de temperatura. Resultado diferente dos clones do grupo PL foi relatado por Paul et al. (2014), que trabalharam com duas cultivares de batata submetidas ao estresse de calor. Estes autores reportaram que ambas as cultivares foram sensíveis, em razão do atraso na tuberização, redução do ciclo vegetativo e produtividade de tubérculos.

No presente trabalho, encontraram-se oito clones tolerantes ao calor, quando se considera a produção de tubérculos; seis desses clones são de ciclo longo e dois de ciclo curto, localizados nos quadrantes I e IV (Figura 1A). Resultado semelhante foi obtido por Rykaczewska (2013), que trabalhou com seis cultivares 
de batata de diferentes ciclos vegetativos e relatou que clones tolerantes foram observados em diferentes grupos de maturação (ciclo curto e intermediário).
Com relação à massa específica de tubérculos, sete clones foram considerados tolerantes a altas temperaturas e responsivos a temperaturas amenas,
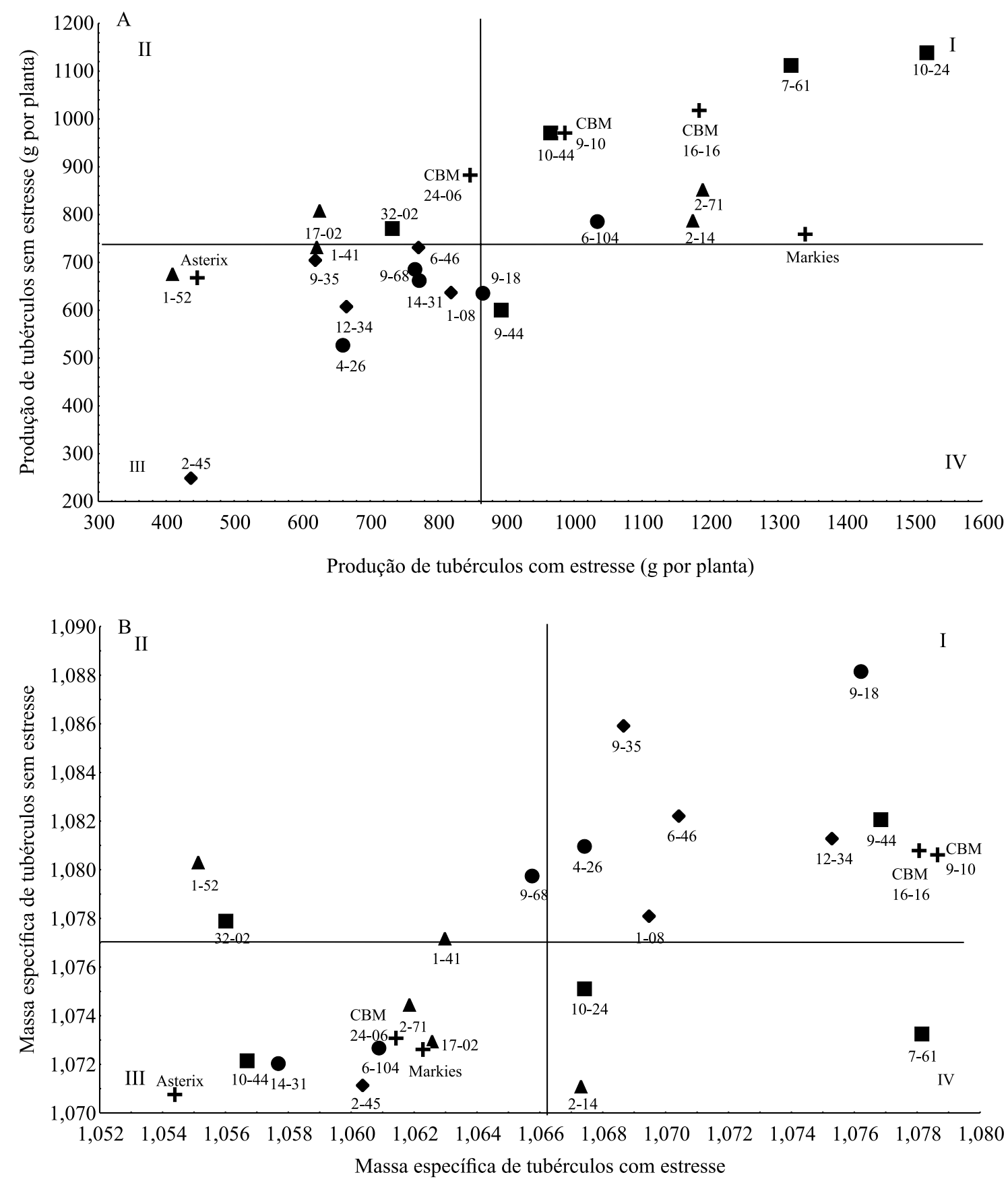

$\bullet \mathrm{PC} \square \mathrm{PL} \bullet \mathrm{TC} \Delta \mathrm{TL}+\mathrm{TE}$

Figura 1. Relação entre as médias de produção total de tubérculos (A) e massa específica de tubérculos (B) dos grupos de clones, sob temperaturas amenas (sem estresse) e sob estresse de calor: PC, tuberização precoce e ciclo vegetativo curto; PL, tuberização precoce e ciclo vegetativo longo; TC, tuberização tardia e ciclo vegetativo curto; TL, tuberização tardia e ciclo vegetativo longo; TE, testemunhas. 
quatro deles do grupo TC, dois do PC e um do PL. Seis clones ficaram no quadrante III, ou seja, têm baixa massa específica, quando avaliadas tanto em condições de temperaturas amenas quanto de temperaturas elevadas (Figura 1 B). Harahagazwe et al. (2012) também relataram redução de massa específica dos tubérculos de batata submetida a condições de estresse de calor. Os autores trabalharam com cinco clones do Centro Internacional de la Papa (CIP) tolerantes ao calor, três cultivares sob estresse e um sem estresse de calor, e verificaram produtividade de matéria seca de 9,7 a 11,6 $\mathrm{Mg} \mathrm{ha}^{-1}$, na condição favorável e de 2,4 a 3,7 $\mathrm{Mg} \mathrm{ha}^{-1}$ na desfavorável.

Os clones-testemunhas tolerantes ao calor, CBM 09-10 e CBM 16-16, também se situaram no quadrante I, bem como a cultivar Markies, o que mostra o bom desempenho destes clones em condições diferentes de temperatura. A cultivar Asterix situouse no quadrante III, o que mostra a falta de adaptação desta cultivar ao estresse de calor.

Ao associar os grupos de clones com a tolerância ao calor e a responsividade a temperaturas amenas, pode-se dizer que foram identificados seis clones IRF 10-24, IRF 7-61, IRF 2-71, IRF 2-14, IRF 6-104 e IRF 10-44 -, que apresentaram médias superiores de produção de tubérculos, e sete clones - IRF 9-35, IRF 9-18, IRF 4-26, IRF 6-46, IRF 1-08, IRF 12-34, IRF 9-44 - quanto à massa específica que, quando submetidos ao estresse, responderam muito bem à melhoria do ambiente (Figura 1).

Com relação à taxa de crescimento da cultura (TCC), os valores máximos foram atingidos entre $55 \mathrm{DAE}$ (PL) e 56,6 DAE (TC). O grupo PL apresentou TCC superior ao dos demais grupos, praticamente durante todo o ciclo (Figura $2 \mathrm{~A}$ ). $\mathrm{O}$ grupo $\mathrm{PC}$ foi o que apresentou a menor taxa de crescimento. Entre as testemunhas, a 'Asterix' apresentou crescimento máximo de 3,55 g MS por planta, por dia, aos 57,4 DAE, enquanto a 'Markies' apresentou 4,19 g MS por planta, por dia, aos 56,7 DAE.

O grupo PL apresentou a maior taxa de tuberização (3,96 g MS por planta, por dia) aos 58,9 DAE (Figura $2 \mathrm{~B}$ ). O grupo TL apresentou tuberização máxima aos 61,0 DAE, com apenas 2,22 g MS por planta, por dia. O grupo PC apresentou menor taxa de tuberização $(2,11 \mathrm{~g}$ MS por planta, por dia) aos 59,9 DAE. Silva et al. (2009) trabalharam com dois clones de ciclo longo e dois de ciclo curto, a temperaturas acima de $20^{\circ} \mathrm{C}$, e também verificaram que os clones de ciclo longo apresentaram taxas de tuberização superiores às dos clones de ciclo curto.

No que se refere à matéria seca da parte aérea, o grupo TL atingiu o máximo desenvolvimento aos 70,2 DAE (126,6 g por planta). O grupo PL atingiu o máximo aos $66,4 \mathrm{DAE}$, com $64,1 \mathrm{~g}$ por planta, quase $50 \%$ inferior ao grupo TL (Figura $2 \mathrm{C}$ ). Os grupos que apresentaram tuberização precoce (PC e PL) apresentaram menor acúmulo de matéria seca da parte aérea do que os de tuberização tardia (TC e TL). Esta diferença ocorreu porque, nos grupos com tuberização precoce, houve aumento da distribuição de matéria seca para os tubérculos, o que resultou em menor desenvolvimento da parte aérea, ou seja, maior dreno para os tubérculos, conforme já relatado por Kooman \& Rabbinge (1996).

Quanto à matéria seca dos tubérculos, o grupo PL atingiu o ponto de máximo aos 89 DAE, com $176,08 \mathrm{~g}$ por planta, enquanto o grupo TL atingiria o máximo além dos limites de colheita estabelecidos (90 DAE). Possivelmente, o máximo seria em torno de 101,0 DAE, com 99,27 g por planta. Os grupos de ciclo curto (PC e TC) apresentaram conteúdo de matéria seca dos tubérculos cerca de $31 \%$ menor no final do ciclo (Figura 2 D). Para Levy \& Veilleux (2007), os clones de ciclo curto, geralmente, têm menor potencial produtivo em consequência do curto período de enchimento dos tubérculos, enquanto os clones de ciclo longo retêm a parte aérea verde por mais tempo e acumulam maior produção durante um período prolongado. Segundo estes últimos autores, a combinação de tolerância ao calor com ciclo longo é desejável, para a obtenção de alta produtividade de tubérculos em climas quentes.

Quanto ao índice de colheita, constatou-se que o grupo PL foi superior aos demais, durante praticamente todo o ciclo, com $76,6 \%$ aos 83,6 DAE, o que mostra que a partição de matéria seca para os tubérculos foi mais rápida, ou seja, com maior dreno. $\mathrm{O}$ grupo TL atingiria o máximo além dos limites estabelecidos de colheita (90 DAE), possivelmente, em torno de 103,2 DAE, com apenas 48,0\% (Figura 2 E). Hancock et al. (2014) também relataram que genótipos de batata condicionados a elevadas temperaturas de $30^{\circ} \mathrm{C}$ de dia e $20^{\circ} \mathrm{C}$ de noite exibiram mudanças na alocação de biomassa do tubérculo para a parte aérea, o que resultou em índice de colheita significativamente reduzido, ou seja, de baixa produção de tubérculos por planta. 
Quanto à produção de tubérculos, merece destaque o grupo PL, que atingiria o máximo além dos limites estabelecidos de colheita (90 DAE), em torno de 100,2 DAE, com 1.323,6 g por planta. Entre as testemunhas, a 'Markies' apresentou a maior produção, que atingiria o máximo aos 99,2 DAE, com 1.085,9 g por planta (Figura 2 F). Van Dam et al. (1996) trabalharam com duas cultivares, a temperaturas elevadas de $30^{\circ} \mathrm{C}$
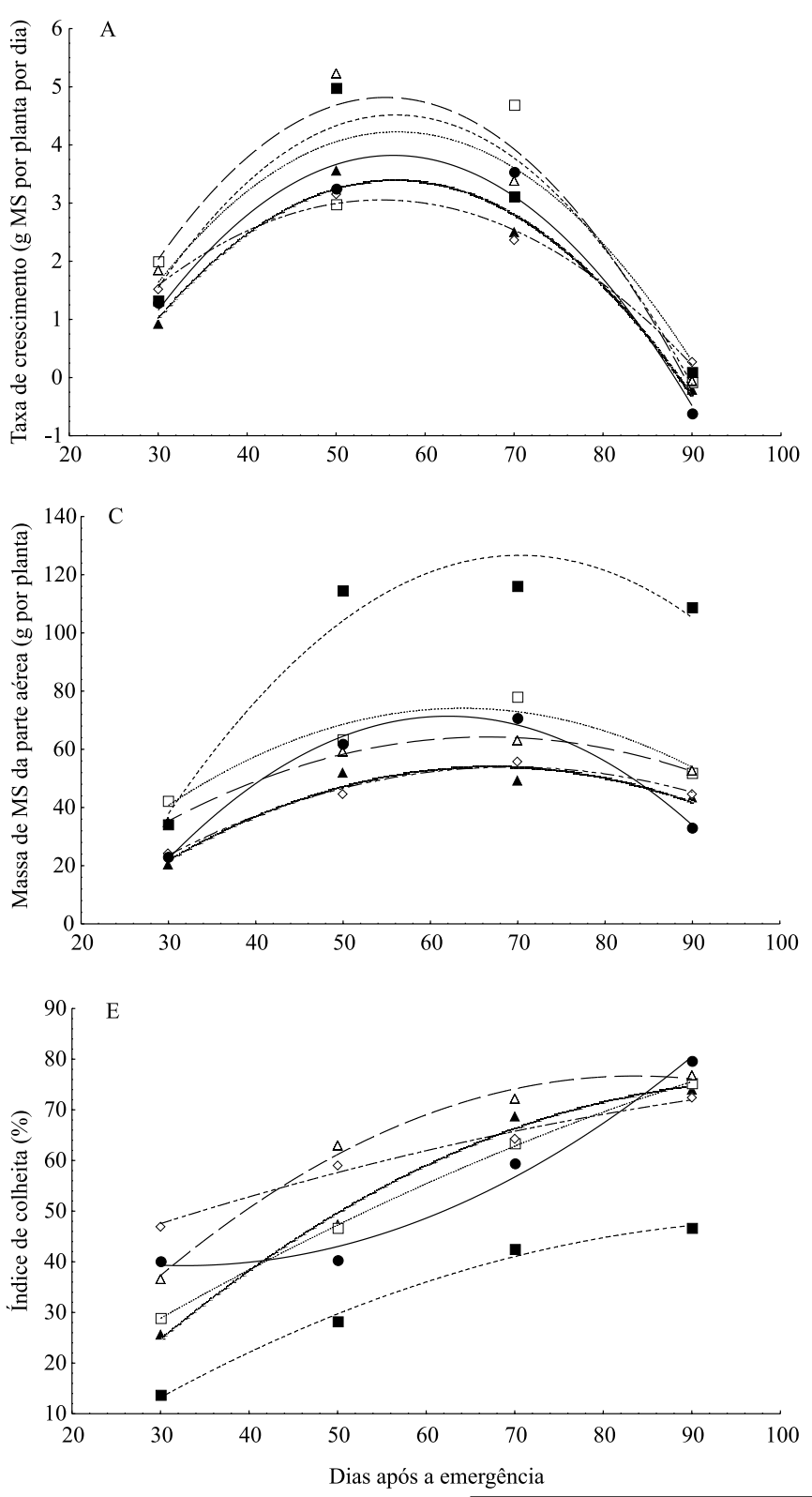

$\Delta$ Asterix $\square$ Markies $\diamond \mathrm{PC} \quad \triangle \mathrm{PL} \quad \bullet \mathrm{TC} \quad \mathbf{\square} \mathrm{TL}$

Figura 2. Taxa de crescimento da cultura (A), taxa de tuberização (B), massa de matéria seca (MS) da parte aérea (C) e dos tubérculos (D), índice de colheita (E) e produção total de tubérculos (F) dos grupos de clones e testemunhas, ao longo do ciclo vegetativo: PC, tuberização precoce e ciclo vegetativo curto; PL, tuberização precoce e ciclo vegetativo longo; TC, tuberização tardia e ciclo vegetativo curto; TL, tuberização tardia e ciclo vegetativo longo.

de dia e $24^{\circ} \mathrm{C}$ de noite, e evidenciaram que o genótipo de ciclo longo foi mais eficiente na tuberização, porém, a taxa de crescimento dos tubérculos decresceu significativamente, em consequência das temperaturas elevadas.

A cultivar Markies - o genótipo mais tolerante ao calor - apresentou comportamento semelhante ao do grupo PL. A cultivar Asterix apresentou
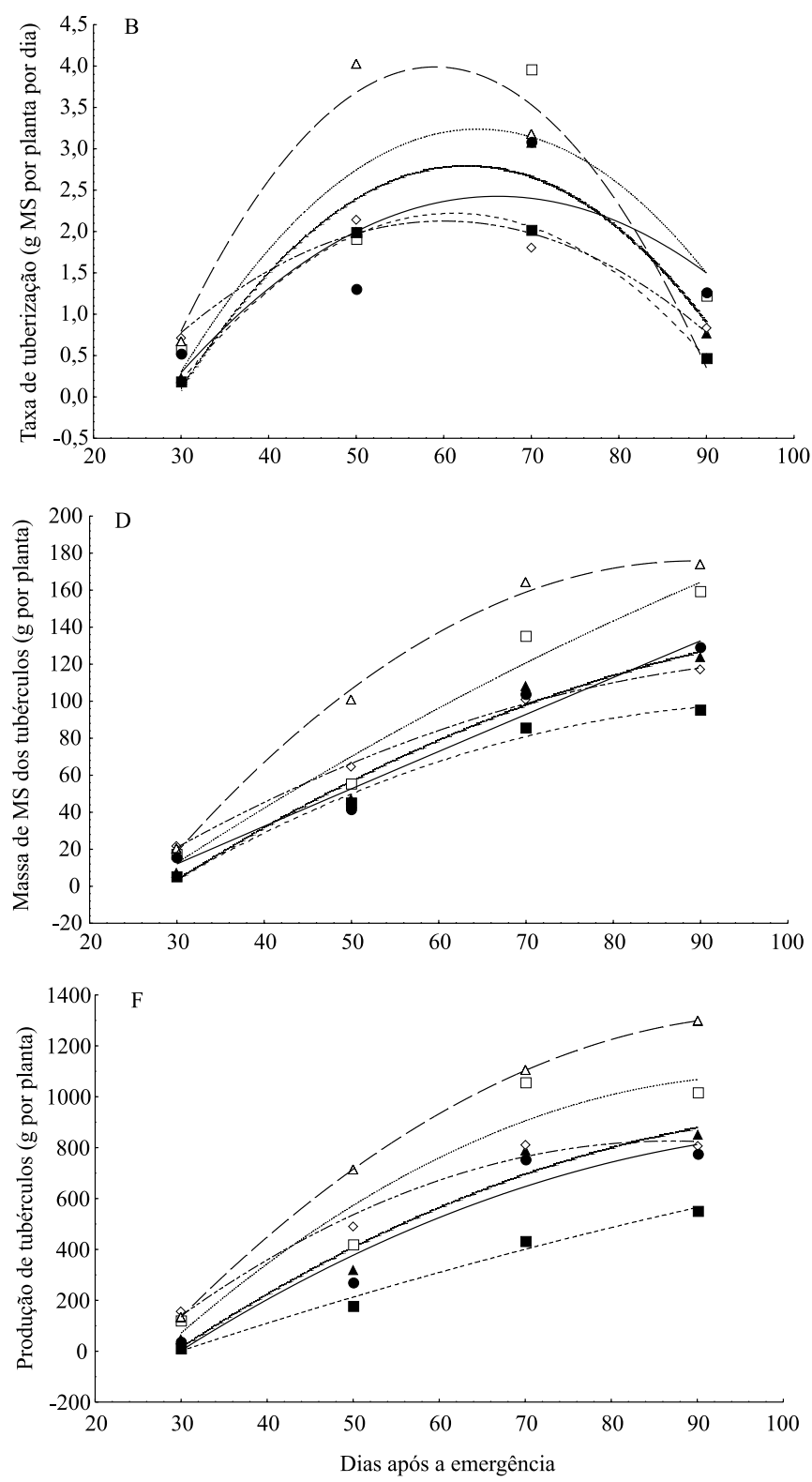

Dias após a emergência 
comportamento similar aos dos grupos de clones de ciclo curto, que entram em senescência mais cedo. Assim, esses genótipos apresentam período de enchimento de tubérculos reduzido, o que prejudica sua produtividade.

Os índices morfofisiológicos contribuem para o entendimento do comportamento dos diferentes grupos de clones sob estresse de calor. Como exemplo, o grupo PL sempre mostrou valores superiores de todos os índices, exceto o de matéria seca da parte aérea. A maior produção de tubérculos deste grupo é consequência do período mais prolongado de enchimento dos tubérculos, que favorece a mobilização de maior quantidade de fotoassimilados. Este resultado é apoiado tanto pela taxa de crescimento da cultura (Figura $2 \mathrm{~A}$ ), quanto pela taxa de tuberização (Figura $2 \mathrm{~B}$ ) e índice de colheita (Figura $2 \mathrm{E}$ ).

Os clones de tuberização precoce e ciclo vegetativo longo são mais produtivos do que os dos demais grupos, tanto em condição de estresse de calor, como de temperaturas mais amenas. Assim, uma boa estratégia para melhorar a produtividade de tubérculos, em condições tropicais, seria a seleção de genótipos que apresentam tuberização precoce e ciclo vegetativo mais longo.

\section{Conclusão}

Os clones de tuberização precoce e ciclo vegetativo longo apresentam maior tolerância ao calor e maior produção de tubérculos do que os clones dos demais grupos.

\section{Agradecimentos}

Ao Conselho Nacional de Desenvolvimento Científico e Tecnológico (CNPq), por concessão de bolsa; à Fundação de Apoio à Pesquisa do Estado de Minas Gerais (Fapemig), por auxílio financeiro; e ao Programa de Melhoramento Genético de Batata da Universidade Federal de Lavras (Probatata), por apoio logístico.

\section{Referências}

AIEN, A.; KHETARPAL, S.; PAL, M. Photosynthetic characteristics of potato cultivars grown under high temperature. American-Eurasian Journal of Agricultural and Environmental Science, v.11, p.633-639, 2011.
BENITES, F.R.G.; PINTO, C.A.B.P. Genetic gains for heat tolerance in potato in three cycles of recurrent selection. Crop Breeding and Applied Biotechnology, v.11, p.133-140, 2011. DOI: $10.1590 /$ S1984-70332011000200005.

FISCHER, L.; LIPAVSKA, H.; HAUSMAN, J.-F.; OPATRNY, Z. Morphological and molecular characterization of a spontaneously tuberizing potato mutant: an insight into the regulatory mechanisms of tuber induction. BMC Plant Biology, v.8, article 117, 2008. DOI: 10.1186/1471-2229-8-117.

HANCOCK, R.D.; MORRIS, W.L.; DUCREUX, L.J.M.; MORRIS, J.A.; USMAN, M.; VERRALL, S.R.; FULLER, J.; SIMPSON, C.G.; ZHANG, R.; HEDLEY, P.E.; TAYLOR, M.A. Physiological, biochemical and molecular responses of the potato (Solanum tuberosum L.) plant to moderately elevated temperature. Plant, Cell and Environment, v.37, p.439-450, 2014. DOI: 10.1111/ pce. 12168.

HARAHAGAZWE, D.; LEDENT, J.F.; RUSUKU, G. Growth analysis and modelling of CIP potato genotypes for their characterization in two contrasting environments of Burundi. African Journal of Agricultural Research, v.7, p.6173-6185, 2012. DOI: $10.5897 / A J A R 10.781$.

HAVERKORT, A.J.; VERHAGEN, A. Climate change and its repercussions for the potato supply chain. Potato Research, v.51, p.223-237, 2008. DOI: 10.1007/s11540-008-9107-0.

JHA, U.C.; BOHRA, A.; SINGH, N.P. Heat stress in crop plants: its nature, impacts and integrated breeding strategies to improve heat tolerance. Plant Breeding, v.133, p.679-701, 2014. DOI: $10.1111 /$ pbr. 12217 .

KOOMAN, P.L.; RABBINGE, R. An analysis of the relation between dry matter allocation to the tuber and earliness of a potato crop. Annals of Botany, v.77, p.235-242, 1996. DOI: 10.1006/ anbo.1996.0027.

LAMBERT, E. de S.; PINTO, C.A.B.P.; MENEZES, C.B. de. Potato improvement for tropical conditions: II. Selection indices and efficiency of indirect selection. Crop Breeding and Applied Biotechnology, v.6, p.185-193, 2006b. DOI: 10.12702/1984-7033. v06n03a01.

LAMBERT, E. de S.; PINTO, C.A.B.P.; MENEZES, C.B. de. Potato improvement for tropical conditions: I. Analysis of stability. Crop Breeding and Applied Biotechnology, v.6, p.129-135, 2006a. DOI: 10.12702/1984-7033.v06n02a03.

LEVY, D.; VEILLEUX, R.E. Adaptation of potato to high temperatures and salinity: a review. American Journal of Potato Research, v.84, p.487-506, 2007. DOI: 10.1007/BF02987885.

MENEZES, C.B. de; PINTO, C.A.B.P.; NURMBERG, P.L.; LAMBERT, E. de S. Avaliação de genótipos de batata (Solanum tuberosum L.) nas safras "das águas" e de inverno no sul de Minas Gerais. Ciência e Agrotecnologia, v.23, p.776-783, 1999.

MIENIE, A.; DE RONDE, J.A. A comparison of drought stress and heat stress in the leaves and tubers of 12 potato cultivars. South African Journal of Science, v.104, p.156-159, 2008.

MORRIS, W.L.; HANCOCK, R.D.; DUCREUX, L.J.M.; MORRIS, J.A.; USMAN, M.; VERRALL, S.R.; SHARMA, S.K.; BRYAN, G.; MCNICOL, J.W.; HEDLEY, P.E.; TAYLOR, M.A. 
Day length dependent restructuring of the leaf transcriptome and metabolome in potato genotypes with contrasting tuberization phenotypes. Plant, Cell and Environment, v.37, p.1351-1363, 2014. DOI: $10.1111 /$ pce. 12238 .

PAUL, S.; GOGOI, N.; SARMA, B.; BAROOWA, B. Biochemical changes in potato under elevated temperature. Indian Journal of Plant Physiology, v.19, p.36-42, 2014. DOI: 10.1007/ s40502-014-0066-y.

PINTO, C.A.B.P.; TEIXEIRA, A.L.; NEDER, D.G.; ARAÚJO, R.R.; SOARES, A.R.O.; RIBEIRO, G.H.M.R.; LEPRE, A.L. Potencial de clones elite de batata como novas cultivares para Minas Gerais. Horticultura Brasileira, v.28, p.399-405, 2010. DOI: $10.1590 / \mathrm{S} 0102-05362010000400004$

RIBEIRO, G.H.M.R.; PINTO, C.A.B.P.; FIGUEIREDO, I.C.R.; MOREIRA, C.M.; LYRA, D.H. Seleção de famílias para aparência dos tubérculos e tolerância a temperaturas elevadas em batata. Bragantia, v.73, p.390-398, 2014. DOI: 10.1590/1678-4499.0108.

RODRIGUES, G.B.; PINTO, C.A.B.P.; BENITES, F.R.G.; MELO, D.S. Seleção para duração do ciclo vegetativo em batata e relação com a produtividade de tubérculos. Horticultura Brasileira, v.27, p.280-285, 2009. DOI: 10.1590/S0102-05362009000300003.

ROLANDO, J.L.; RAMÍREZ, D.A.; YACTAYO, W.; MONNEVEUX, P.; QUIROZ, R. Leaf greenness as a drought tolerance related trait in potato (Solanum tuberosum L.). Environmental and Experimental Botany, v.110, p.27-35, 2015. DOI: 10.1016/j.envexpbot.2014.09.006.
RYKACZEWSKA, K. The effect of high temperature occurring in subsequent stages of plant development on potato yield and tuber physiological defects. American Journal of Potato Research, V.92, p.339-349, 2015. DOI: 10.1007/s12230-015-9436-X.

RYKACZEWSKA, K. The impact of high temperature during growing season on potato cultivars with different response to environmental stresses. American Journal of Plant Sciences, v.4, p.2386-2393, 2013. DOI: 10.4236/ajps.2013.412295.

SILVA, F.L. da; PINTO, C.A.B.P.; ALVES, J.D.; BENITES, F.R.G.; ANDRADE, C.M.; RODRIGUES, G.B.; LEPRE, A.L.; BHERING, L.L. Caracterização morfofisiológica de clones precoces e tardios de batata visando à adaptação a condições tropicais. Bragantia, v.68, p.295-302, 2009. DOI: 10.1590/ S0006-87052009000200002.

SILVA, L.A.S.; PINTO, C.A.B.P. Duration of the growth cycle and the yield potential of potato genotypes. Crop Breeding and Applied Biotechnology, v.5, p.20-28, 2005. DOI: 10.12702/1984-7033. v05n01a03.

VAN DAM, J.; KOOMAN, P.L.; STRUIK, P.C. Effects of temperature and photoperiod on early growth and final number of tubers in potato (Solanum tuberosum L.). Potato Research, v.39, p.51-62, 1996. DOI: 10.1007/BF02358206.

ZOMMICK, D.H.; KNOWLES, L.O.; PAVEK, M.J.; KNOWLES, N.R. In-season heat stress compromises postharvest quality and low-temperature sweetening resistance in potato (Solanum tuberosum L.). Planta, v.239, p.1243-1263, 2014. DOI: 10.1007/ s00425-014-2048-8.

Recebido em 25 de novembro de 2014 e aprovado em 29 de maio de 2015 